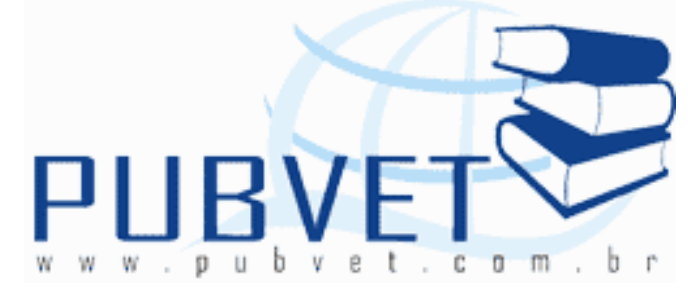

PUBVET, Publicações em Medicina Veterinária e Zootecnia.

\title{
Importância da escolha de receptoras em um programa de transferência de embriões em bovinos
}

Marília Torres Honorato ${ }^{1}$, Rafael Alves Costa Ferro ${ }^{2}$, Diogo Alves da Costa Ferro ${ }^{2}$, Klayto José Conçalves dos Santos ${ }^{2}$,Miliane Alves da Costa ${ }^{3}$, Joaquim Luiz Rodrigues Filho ${ }^{3}$

1 Zootecnista pela UEG-UnU de São Luís de Montes Belos

2 Docentes do Curso de Zootecnia da UEG-UnU de São Luís de Montes Belos

3 Graduandos em Zootecnia pela UEG-UnU de São Luís de Montes Belos

\section{Resumo}

A utilização de biotecnologias reprodutivas representa cada vez mais a evolução da produção animal no Brasil e no mundo. A Inseminação Artificial em bovinos veio como a pioneira dessa evolução, seguida pela Transferência de Embriões (TE) convencional que trouxe a Aspiração Folicular guiada por ultra-sonografia para produção in vitro de embriões bovinos, possibilitando o incremento da genética dos rebanhos, em quantidade e qualidade. Objetivou-se descrever os aspectos relacionados a um programa de transferência de embriões, relatando que em posição de destaque encontram-se as receptoras responsáveis pela gestação de animais de genética superior. O programa de Aspiração Folicular veio como a evolução da TE convencional, tornando os processos mais práticos, viáveis e eficientes, porém não se deve esquecer que os envolvidos nos processos devem possuir experiência e habilidade profissional, pois eles são 
HONORATO, M.T. et al. Importância da escolha de receptoras em um programa de transferência de embriões em bovinos. PUBVET, Londrina, V. 7, N. 19, Ed. 242, Art. 1601, Outubro, 2013.

responsáveis por viabilizar sua execução. Os principais aspectos ligados à realização dessa biotecnologia são: o embrião, o sêmen utilizado e a receptora, destacando ainda a importância do aspecto sanitário que o embrião livre de doenças infecto-contagiosas deve apresentar. As receptoras desempenham um papel muito importante, trazendo consigo a responsabilidade da gestação, parto e criação de um bezerro de elevado valor genético que irá representar o melhoramento genético animal proveniente de uma doadora e um touro com grande valor agregado. Cuidados com a sanidade, nutrição e bem-estar dessas fêmeas são fundamentais para que elas possam responder aos tratamentos hormonais a elas impostos e assim cumpram o objetivo delas dentro de uma propriedade que é um parto por ano e, além disso, desmamar um bezerro pesado e saudável.

Palavras-chave: Aspiração folicular, fertilização in vitro, gestação, ultrasonografia

\section{Importance of choosing a program receiving embryo transfer in cattle}

\section{Abstract}

The usage of reproductive biotechnologies is even more representing the evolution of bovine production in Brazil and around the world. The artificial insemination in cattle came as the pioneer of this evolution, followed by conventional Embryos Transference (ET) that brought the Follicular Aspiration guided by the ultrasonography for the production of bovine embryos in vitro, making the enhancement of the cattle genetics possible, in quantity and quality. Describing the aspects related to embryos transference program was the aiming goal, reporting that the receptors responsible for the gestation of genetic superior bovine are in a position of prominence. The Follicular Aspiration program came as the evolution of the conventional ET, making the processes more practical, viable and efficient, but it should not 
HONORATO, M.T. et al. Importância da escolha de receptoras em um programa de transferência de embriões em bovinos. PUBVET, Londrina, V. 7, N. 19, Ed. 242, Art. 1601, Outubro, 2013.

be forgotten that the ones involved in the processes must have professional experience and ability, because they are responsible for making the process execution viable. The main aspects related to the performing of this biotechnology are: the embryo, the semen to be utilized and the receptor, highlighting the importance of the sanitary aspects that the embryos free from infectious diseases must present. The receptors play a very important role, having the responsibility of gestation itself, to deliver and take care of the high genetic value calf that will represent the bovine genetic improvement from a cow (donor) and an ox (donor) of great value. Cares with sanity, nutrition and welfare of these females are fundamental so that they can respond to the hormonal treatments imposed to them and with that accomplish their objective inside a property that is one delivery per year and more, wean a big and healthy calf.

Keywords: Follicular aspiration, gestation, in vitro fertilization, ultrasonography.

\section{INTRODUÇÃO}

A evolução da produtividade da pecuária brasileira está intimamente associada às evoluções tecnológicas e científicas, fazendo uso de várias biotecnologias reprodutivas que vem sendo desenvolvidas, utilizadas e aprimoradas com objetivo principal de elevar a eficiência reprodutiva dos animais geneticamente superiores, aumentando o número de descendentes com essa carga genética, em um curto período de tempo.

Quando falamos das principais biotecnologias utilizadas no Brasil, não se deve deixar de lado a Inseminação Artificial (IA), pois foi a primeira biotecnologia adotada nos sistemas de produção brasileiros que tem como intuito a multiplicação de animais de alto valor genético. Com a utilização inicialmente de esquemas de ovulações múltiplas, recuperação e transferência de embriões, mais conhecida como Multiple Ovulation and Embryo Transfer (MOET) ou ainda transferência de embrião (TE) 
HONORATO, M.T. et al. Importância da escolha de receptoras em um programa de transferência de embriões em bovinos. PUBVET, Londrina, V. 7, N. 19, Ed. 242, Art. 1601, Outubro, 2013.

convencional, intimamente associado acriopreservação de embriões. Na década de 80 a cadeia produtiva de bovinos passou assim a ter uma poderosa ferramenta para aumentar o número de gestações de origem de fêmeas de alto mérito genético (Rodrigues, 2001).

De acordo com Thibier (2000), a produção embrionária fazendo uso da TE é uma biotécnica difundida mundialmente e vem apresentando um crescimento acentuado com mais de 500.000 embriões sendo colhidos e transferidos ou congelados anualmente.

Diz-se da Fertilização In Vitro (FIV) a terceira geração de biotecnologia aplicada ao Melhoramento Genético Animal, após a IA e a TE. No início, na década de 90, com a utilização da aspiração folicular guiada por ultrasonografia seguida pela produção in vitro de embriões, elevou cada vez mais a expectativa em torno do incremento da produtividade das fêmeas (Renesto, 2004).

Para que um programa de TE obtenha sucesso em uma propriedade rural, onde vários indivíduos diferentes e com grau de instrução diferenciado se encontram unidos, uma interação dessa equipe tem que acontecer, onde todos devem "falar a mesma língua" de modo que eles se entendam. Além disso, a correta aplicação da técnica e uma administração eficiente da propriedade têm papel muito importante (Reichenbach et al., 2002).

Mesmo com suas vantagens a TE convencional ainda apresenta algumas limitações, como a discrepância nas respostas aos tratamentos hormonais e os esforços reunidos para a realização destes que levam a uma considerável restrição ao programa. Além destes aspectos, a seleção adequada e o manejo adequado das receptoras de embriões são indispensáveis para o sucesso da $\mathrm{TE}$, uma vez que a mortalidade após a transferência é ainda significativa e limita muito a eficiência desse método (Bóet al., 2002).

As receptoras têm papel muito importante num programa de transferência de embriões, bons manejos nutricionais e sanitários e também o bem-estar desses animais tem que ser empregados para que elas possam 
HONORATO, M.T. et al. Importância da escolha de receptoras em um programa de transferência de embriões em bovinos. PUBVET, Londrina, V. 7, N. 19, Ed. 242, Art. 1601, Outubro, 2013.

responder aos tratamentos hormonais aos quais são submetidas, estando aptas a receber um embrião, manter uma gestação, ter um parto normal e ainda desmamarem bezerros saudáveis.

Objetivou-se descrever os aspectos relacionados a um programa de transferência de embriões, relatando que em posição de destaque encontram-se as receptoras responsáveis pela gestação de animais de genética superior.

\section{REVISÃO DELITERATURA}

\subsection{Transferência de Embriões em Bovinos}

A Transferência de Embriões tem grande importância no melhoramento zootécnico, porque acelera e confere maior precisão no processo de seleção animal. Além de conferir a animais com distúrbios reprodutivos adquiridos sem caracterização genética, que sejam geneticamente superiores, a possibilidade de se reproduzirem e também impedir que o descarte destes seja realizado precocemente (Reichenbach et al., 2002).

Analisando o processo de transferência de embriões como um todo, três níveis de risco estão envolvidos, são eles: o embrião que será transferido, o sêmen que é utilizado para fecundação dos oócitos"in vivo" ou "in vitro" e a receptora. Faz-se necessário que sejam tomadas medidas que diminuam a possibilidade de contaminação do embrião em todos os três níveis, conferindo ao processo de transferência de embriões menor risco de transmissão de doença (Parra et al., 2008).

Levando em consideração que na natureza, o potencial genético e reprodutivo dos animais fica limitado, a transferência de embriões representa uma alternativa substancial no avanço da eficiência reprodutiva. Em bovinos, em média, uma fêmea gera uma cria por ano, ou seja, de oito a dez produtos durante toda a sua vida reprodutiva, já nos machos são de quinze a vinte produtos por ano. Fazendo uso da TE aliada àIA há então 
HONORATO, M.T. et al. Importância da escolha de receptoras em um programa de transferência de embriões em bovinos. PUBVET, Londrina, V. 7, N. 19, Ed. 242, Art. 1601, Outubro, 2013.

ganhos genéticos em larga escala nos programas de melhoramento animal, além de que a seleção passa a ser mais eficiente (rápida e precisa), diminuindo ainda o intervalo entre gerações obtendo vários produtos de doadoras de mérito confirmado (vacas) ou previsível (novilhas) (Costa \& Silva, 2004).

A TE traz uma série de vantagens quando falamos em seleção zootécnica além de um consequente reflexo sobre a produção animal, alguns deles são: seleção das mães dos touros geneticamente superiores para inseminação, aumentando o número de descendentes desses animais, redução do intervalo entre gerações e aumento da velocidade do melhoramento (Andrade et al., 2002). Contribui ainda para ampliar os conhecimentos de fisiologia, patologia e endocrinologia que advém da relação entre embrião, órgãos genitais internos e sistema nervoso central, além de equacionar os problemas relativos à ordem genética e sanitária (Reichenbach et al., 2002).

Para se realizar a TE as instalações na fazenda devem atender a necessidade dos animais, conferindo espaço suficiente para manejar e alojar os animais com o mínimo de estresse e risco de ferimentos, lembrando que a segurança das pessoas que irão manejá-los também tem que ser considerada. É de suma importância que se tenha um tronco com brete, de preferência coberto e com um número suficiente de currais de apartação (Mapletoft \& Stookey, 1999).

\subsubsection{Programa convencional de transferência de embriões}

O objetivo de um programa de TE é triplicaras taxas médias de uma a três gestações/coleta e aumentar a frequência de coletas para seis a oito por ano. Além disso, a transferência ainda veio para mudar o conceito de que o processo de seleção genética e características fenotípicas ficassem restritos ao macho, pois essa biotécnica possibilita a fêmea produzir um maior número de descendentes do que seria possível fisiologicamente, proporcionando ainda, através do congelamento de embriões o transporte 
HONORATO, M.T. et al. Importância da escolha de receptoras em um programa de transferência de embriões em bovinos. PUBVET, Londrina, V. 7, N. 19, Ed. 242, Art. 1601, Outubro, 2013.

internacional de germoplasma sem o risco de transmissão de doenças, a conservação de raças em perigo de extinção dentre outros aspectos (Reichenbach et al., 2002).

\subsubsection{Superovulação aplicada ao programa convencional de transferência} de embriões

A chamada superovulação (SOV) é denominada como o aumento do número fisiológico de ovulações próprias da espécie, induzida via administração de gonadotrofinas. Na espécie bovina, entende-se que houve resposta ao tratamento quando há produção de mais de duas ovulações (Caboevila\&Torquati, 2001).

Devido há alta variabilidade de respostas fornecidas por tratamentos gonadotróficos houve uma motivação para a realização de estudos com intuito de formular protocolos que possam ser capazes de estabilizar e racionalizar os programas de SOV (Andrade et al., 1999). Segundo Bó (2002), o tratamento deve ser realizado no começo de uma onda folicular, antes da seleção do folículo dominante, com intuito de obter a melhor resposta possível.

Vale ressaltar que o tratamento superovulatório não irá promover o desenvolvimento folicular e sim, permitir aqueles folículos que normalmente entrariam em atresia, uma maneira adequada para que continuem seus processos de maturação, resultando na ovulação (Diniz et al., 1999).

São vários os protocolos de SOV existentes, por exemplo, utilizando o cio natural ou em qualquer fase do ciclo estral. No primeiro o tratamento tem início entre o dia oito e doze após a manifestação do estro, juntamente com o início da segunda onda folicular. São realizadas oito aplicações de Hormônio Folículo Estimulante(FSH) de 12 em 12 horas, com objetivo de aumentar o recrutamento dos folículos. Ao terceiro dia realiza-se duas aplicações de prostaglandina para que ocorra a luteólise do corpo lúteo, assim haverá a redução da progesterona e consequente pico de Hormônio Luteinizante(LH), seguida da ovulação (Bó, 2002). 
HONORATO, M.T. et al. Importância da escolha de receptoras em um programa de transferência de embriões em bovinos. PUBVET, Londrina, V. 7, N. 19, Ed. 242, Art. 1601, Outubro, 2013.

O tratamento superovulatório tem objetivo de obter o número superior de embriões fertilizados e transferidos com elevada probabilidade de ocorrência de prenhez (Mapletoftet al., 2002).

O tipo de hormônio e a variação de cada indivíduo são aspectos de grande relevância no desempenho referente à superovulação. O estado em que se encontra o ovário vem se mostrando fator determinante na resposta ao tratamento de SOV, tornando-se uma característica estudada constantemente com intuito de elevar o índice de recuperação de embriões viáveis. Além deste, outros componentes da dinâmica folicular, como por exemplo, o tamanho, as condições dos folículos antrais e a distribuição influenciam a resposta ovulatória mediante tratamento hormonal (Visitinet al., 1999).

\subsubsection{Colheita, exame e avaliação dos embriões}

Deve-se realizar a colheita de embriões preferencialmente, entre o sexto e o oitavo dia após a primeira inseminação das doadoras, pois nesse período o embrião encontra-se flutuando, num filme líquido no lúmen da ponta dos cornos uterinos, o que permite sua captação por meio da técnica de lavagem dos cornos uterinos. Essa colheita, feita com o animal posicionado em estação, é realizada pelo método transcervical com o auxílio de um cateter de borracha ou de plástico flexível contendo um balão inflável na sua extremidade distal. Inicialmente, esse cateter, contendo um mandril de metal em seu lúmen para torná-lo rígido, é introduzido e posicionado em um dos cornos uterinos (Demétrio, 2003).

Posteriormente, o balão é inflado com dez a $20 \mathrm{ml}$ de ar e em seguida é retirado o mandril do interior do cateter, sendo importante destacar que todo manuseio do cateter no interior do útero é auxiliado por palpação retal. O tempo médio necessário para a colheita de embriões é de 20 minutos, sendo igualmente importante conter a doadora. Deve-se atentar ao fato de que o cateter estando corretamente posicionado, os embriões podem ser obtidos sem que haja risco de refluxo do meio de cultivo durante o 
HONORATO, M.T. et al. Importância da escolha de receptoras em um programa de transferência de embriões em bovinos. PUBVET, Londrina, V. 7, N. 19, Ed. 242, Art. 1601, Outubro, 2013.

procedimento de colheita de embriões em ambos os cornos uterinos (Demétrio, 2003).

Com esse método de lavagem por via transcervical, utiliza-se um grande número de lavagens por corno uterino, com intuito de uma maior taxa de recuperação de embriões. Porém, o procedimento leva um grande número de placas a ser analisado, por doadora submetida a colheita, o que exige tempo. Vale ressaltar que, um longo período de exposição dos embriões às condições de ambiente pode repercutir, de maneira negativa, na viabilidade dos mesmos e, como consequência pode comprometer os resultados da inovulação, a fresco ou após a congelação (Munaret al., 2001).

Outros aspectos a serem considerados na técnica diz respeito a grande possibilidade de contaminação do lavado uterino com partículas de suspensão no ar, pêlos, fezes e urina do próprio animal, com suor dos envolvidos no ato da colheita, havendo ainda, o risco de perda de todo o material colhido após movimentação brusca da doadora. Então, com a utilização de um circuito fechado, tem-se que a colheita por via transcervical torna-se uma técnica prática, asséptica e segura para a doadora, com a menor possibilidade de contaminação ou de perda dos embriões. Esse circuito fechado propicia uma maior pressão no interior do corno uterino, o que favorece a recuperação do meio de lavagem intra-uterina infundido (Munar et al., 2001).

Os embriões coletados são transportados do filtro de colheita para placas de Petri com diâmetro de $12 \mathrm{~cm}$, com o auxílio de um estereoscópio faz-se a primeira busca na placa com suaves movimentos circulares, onde toda e qualquer estrutura encontrada é retirada com a ajuda de uma seringa tipo de insulina e ponteira estéril para uma placa menor, contendo gotas do meio de manutenção (Demétrio, 2003).

Os embriões localizados devem ser colocados em outra placa com solução de coleta contendo soro fetal bovino (SFB) ou albumina sérica bovina (BSA), essas soluções devem ser de boa qualidade e esterilizadas. Os embriões encontrados são colocados na placa com meio fresco e lavados 
HONORATO, M.T. et al. Importância da escolha de receptoras em um programa de transferência de embriões em bovinos. PUBVET, Londrina, V. 7, N. 19, Ed. 242, Art. 1601, Outubro, 2013.

novamente em outros banhos. Na avaliação morfológica de um embrião considera-se com relação as estruturas e qualidades os seguintes aspectos: forma esferóide; simetria dos blastômeros; aparência clara e nítida dos blastômeros; tonalidade escura e uniforme; uniformidade da membrana celular; proporcionalidade entre o embrião e fragmentos celulares no espaço perivitelíneo; ausência de fragmentos celulares aderidos à zona pelúcida; compactação dos blastômeros entre si (Goodhand et al., 2005).

Os embriões encontrados na placa de Petri, que já passaram por avaliação morfológica e que foram designados viáveis podem ser congelados ou inovulados em receptoras (Costa, 2005).

\subsubsection{Transferência dos embriões (inovulação)}

A inovulação consiste em depositar o embrião no terço médio-final do corpo uterino ipsilateral ao CL. As receptoras devem ser contidas em um tronco, mantidas em estação e anestesiadas via epidural, o reto esvaziado e a vulva limpa com papel toalha. Para transferência a fresco, o embrião deve sofrer três banhos consecutivos com meio de manutenção para lavagem, após os banhos o embrião é envasado em palhetas de 0,25 ml. A palheta é carregada primeiramente com o meio de manutenção, deixa-se um espaço com ar e logo em seguida se carrega o embrião com meio de manutenção. Posteriormente, a segunda parte de ar é inserida e a última camada novamente com o meio. A palheta contendo o embrião é colocada em uma bainha estéril e em seguida no inovulador, é utilizada uma camisinha sanitária para manter a bainha livre de contaminações (Costa, 2005).

2.1.2 Aspiração folicular guiada por ultra-sonografia para produção in vitro de embriões bovinos

Obter oócitos através da aspiração folicular in vivo é a primeira etapa para a produção in vitro de embriões. Após a recuperação destes oócitos, outros processos como seleção, maturação, fecundação e desenvolvimento 
HONORATO, M.T. et al. Importância da escolha de receptoras em um programa de transferência de embriões em bovinos. PUBVET, Londrina, V. 7, N. 19, Ed. 242, Art. 1601, Outubro, 2013.

são realizados em laboratórios especializados (Senedaet al., 2005).

No início da década de 90, com a introdução da Ovum Pick-up(Punção Folicular), seguida pela produção in vitro de embriões (OPU-PIV), a expectativa no incremento da produtividade das fêmeas aumentou. A aplicação dessa técnica é de grande importância para a multiplicação rápida de animais, e exibe algumas vantagens quando comparada com a MOET (Renesto, 2004).

Nibartet al. (1995), demonstraram que se pode obter até 18 gestações em três meses utilizando a aspiração folicular, enquanto que com a TE convencional, no mesmo período, seria possível obter apenas cinco gestações. Outras vantagens da OPU-PIV são a obtenção de oócitos em qualquer fase do ciclo estral sem utilização de tratamento gonadotrófico (Merton et al., 2003), permitindo realizar repetidas recuperações de oócitos de animais vivos sem trauma aparente do trato reprodutivo, a produção de embriões oriundos de vacas com patologias reprodutivas adquiridas (Rodrigues, 2001), ou vacas prenhez, durante o primeiro trimestre de gestação (Meintjes et al., 1995) ou em novilhas pré-puberes (Brogliatti\& Adams, 1996). Além destas vantagens tem-se a maximização do uso do sêmen, permitindo maior produção de embriões com doses de alto valor comercial e inclusive sêmen sexado (Faber et al., 2003).

Resultados de campo mostram que quando a aspiração folicular é realizada em fases aleatórias do ciclo estral a qualidade dos oócitos não sofre alteração, porém o número de folículos disponíveis para a aspiração revela considerável variação, onde no início da onda é o momento mais favorável devido ao maior número de folículos e pela maior eficiência de captação dos oócitos (Senedaet al., 2005). Hendriksenet al. (2004) mostraram que o folículo dominante é quem reduz o desenvolvimento e a competência dos oócitos pertencentes aos folículos subordinados, então a aspiração realizada nos dias dois a cinco do ciclo estral ou dois a cinco dias após a discrepância do folículo dominante o que poderia conferir à produção in vitro um incremento. 
HONORATO, M.T. et al. Importância da escolha de receptoras em um programa de transferência de embriões em bovinos. PUBVET, Londrina, V. 7, N. 19, Ed. 242, Art. 1601, Outubro, 2013.

A FIV contribui como uma alternativa para a SOV e maior produção de embriões por unidade de tempo quando comparada a TE convencional. Porém, mesmo com os progressos obtidos nos processos de maturação in vitro (MIV), fecundação in vitro (FIV) e cultivo in vitro (CIV) para o desenvolvimento embrionário e da técnica, algumas desvantagens precisam ser melhoradas e solucionadas. As taxas de blastocistos oriundos de oócitos maturados e fertilizados in vitropermanecido relativamente estáticas na última década, onde apenas um terço(Lonergan et al., 1994; Dayan et al., 2000) dos oócitos selecionados morfologicamente antes de serem submetidos a MIV resultam em embriões viáveis (Renesto, 2004).

2.1.2.1 Sequência de procedimentos da aspiração folicular até a avaliação morfológica dos embriões para a transferência

O procedimento de aspiração folicular é realizado utilizando-se equipamento de ultra-som com transdutor conectado a guia de biópsia, com agulhas e linha de aspiração em tubos de centrífuga de $50 \mathrm{ml}$. Com intuito de evitar movimentos peristálticos e desconforto ao animal é feita anestesia epidural e em seguida o transdutor é inserido até o fundo vaginal e, com auxílio da manipulação transretal, os ovários são posicionados para obtenção de uma boa visualização na tela do ultra-som. Os folículos a serem aspirados são posicionados no percurso da linha de punção indicada na tela do ultrasom e quando a agulha está próxima do folículo, o pedal da bomba de vácuo é pressionado e o folículo aspirado (Nibart et al., 1995), o mesmo procedimento tem que ser repetido em todos os folículos visíveis de cada ovário. O material aspirado é transferido para um filtro de colheita de embriões e lavado com a mesma solução utilizada na aspiração. O que resta no filtro é observado em placas de Petri e é feita a busca e contagem dos oócitos e posterior classificação da qualidade. Os oócitos são classificados de acordo com a sua morfologia (número de camadas de células do cumullus e aspecto do citoplasma) em graus I, II, e III (GI, GII e GIII), oócitos sem cumullus(s/c), expandidos (exp), degenerados (deg) e atrésicos (atr), 
HONORATO, M.T. et al. Importância da escolha de receptoras em um programa de transferência de embriões em bovinos. PUBVET, Londrina, V. 7, N. 19, Ed. 242, Art. 1601, Outubro, 2013.

segundo Lonerganet al. (1994).

Os oócitos considerados viáveis são classificados em GI, GII e GIII, colocados em criotubos com meio de maturação em banho Maria a $35^{\circ} \mathrm{C}$. $\mathrm{O}$ transporte é feito em meio de maturação líquida e atmosfera de $5 \%$ de $\mathrm{CO}_{2}$ e $5 \%$ de $\mathrm{O}_{2}$. O tempo médio de transporte pode variar de seis a oito horas, não devendo ultrapassar oito horas do início da aspiração na primeira vaca até a chegada dos oócitos ao laboratório. Quando chegam ao laboratório são lavados três vezes em meio de lavagem, e em seguida transferidos para placas de Petri, onde permanecem incubados por 24 horas a $38,5^{\circ} \mathrm{C}$ em atmosfera de $5 \%$ de $\mathrm{CO}_{2}$ (Renesto, 2004).

Depois são lavados mais três vezes em meio de fecundação e transferidos para microgotas de meio de fecundação, o sêmen é adicionado e então são incubados em temperatura de $39^{\circ} \mathrm{C}$ por 18 a 20 horas, com atmosfera de $5 \%$ de $\mathrm{CO}_{2}$ em ar, para fecundação. Após o tempo de fecundação, os zigotos são lavados por três vezes e as estruturas transferidas para meio de cultivo, recobertas por óleo mineral, permanecendo nestas por um período de seis a oito dias até os zigotos atingirem os estádios de mórula (Mo) e blastocisto ( $\mathrm{Bl})$. O meio de cultivo é renovado a cada microgota no terceiro e quinto dia (feeding) e no sexto e sétimo dia é observado o desenvolvimento embrionário. Sete dias após a primeira IA, os embriões são recolhidos pelo método não cirúrgico e recuperados em filtro próprio, em seguida, são rastreados e transferidos para uma placa de Petri para avaliação do estágio de desenvolvimento do embrião (mórula, blastocisto, blastocisto em expansão e blastocisto eclodido), quanto ao formato e integridade da zona pelúcida e a morfologia são classificados em normais, degenerados, não fertilizados e sem zona pelúcida (Boland et al., 1991).

\subsection{Aspectos Relacionados às Doadoras de Embriões}

Para dar início à seleção de doadoras, deve-se ter o controle 
HONORATO, M.T. et al. Importância da escolha de receptoras em um programa de transferência de embriões em bovinos. PUBVET, Londrina, V. 7, N. 19, Ed. 242, Art. 1601, Outubro, 2013.

zootécnico, que é um requisito de grande importância para fazer o uso de tal biotecnologia, uma vez que uma criteriosa avaliação se faz necessária, devido à influência que essas fêmeas exercerão sobre as próximas gerações, fazendo uso de animais geneticamente superiores (Simão, 2004).

Além dos aspectos zootécnicos é de fundamental importância que as doadoras possam fornecer embriões com qualidade sanitária, pois este é um dos principais requisitos para o trânsito internacional (Sutmoller, 1996). Em âmbito nacional o aspecto sanitário dos embriões passa a ser relevante principalmente com relação a áreas livres de Febre Aftosa (Brasil, 1999).

A doadora tem que ser examinada clinicamente por um Médico Veterinário credenciado estando livre de doenças infecto-contagiosas, o rebanho do qual tenham origem deve estar livre de sinais clínicos de febre aftosa, peste bovina e não estarem em zona infectada por trinta dias antes e depois da coleta. Quanto à legislação brasileira e dos países do MERCOSUL quando se referem a normas sanitárias para a produção de embriões é mais severa, pois exige que o rebanho de doadoras não tenha sido afetado por febre aftosa ou estomatites vesiculares nos 90 dias precedentes à coleta de embriões e que as doadoras sejam testadas contra Brucelose e Tuberculose nos trinta dias subsequentemente à coleta (Parra, et al., 2008).

Além do controle zootécnico e sanitário outro aspecto está intimamente relacionado ao sucesso da utilização da $T E$, o estado nutricional, pois não é interessante uma dieta que esteja com excesso ou até mesmo falta de energia que são critérios que vão interferir negativamente a produção de embriões (Rigolonet al., 2000). O hormônio responsável por regular a liberação do Hormônio Liberador de Gonadotrofina $(\mathrm{GnRH})$, que reflete o estado nutricional e as reservas energéticas é um hormônio derivado dos adipócitos, denominado leptina, que exerce importante papel na transmissão dos efeitos da condição metabólica do animal sobre sua fertilidade (Foster \&Nagatani, 1999). Quando em baixas condições nutricionais, os níveis de leptina e gonadotrofina estão relativamente baixos, sendo revertidas as concentrações de FSH e LH após 
HONORATO, M.T. et al. Importância da escolha de receptoras em um programa de transferência de embriões em bovinos. PUBVET, Londrina, V. 7, N. 19, Ed. 242, Art. 1601, Outubro, 2013.

aplicação exógena desse hormônio. Existem relevantes evidências de que a leptina é o sinal metabólico para inibir a atividade reprodutiva em condições nutricionais deficientes e reservas energéticas inadequadas (Cunningham et al., 1999).

Com a avaliação periódica das fêmeas submetidas a punções foliculares o monitoramento da ocorrência e intensidade de lesões subsequentes ao procedimento é realizado com eficiência (Senedaet al., 2005). Os resultados obtidos por Viana et al. (2002) mostraram que perfurações do fundo do saco vaginal foram rapidamente cicatrizadas, e em apenas duas ocasiões foram constatadas irritações transitórias da vagina e cérvix. Diferente do observado na região vaginal, Viana et al. (2003) encontraram incidência significativa de alterações na consistência ou mobilidade dos ovários. As perfurações dos ovários podem levar a aderência e fibrose, especialmente em vacas submetidas a muitas sessões de aspiração. Vale ressaltar o quanto as variáveis técnicas e a habilidade do operador na ocorrência dessas lesões são importantes.

Segundo Williams (2001), para fazer a inclusão de uma doadora em um programa de TE convencional ela tem que estar com pelo menos 60 dias pós-parto, ser observado rigorosamente a regularidade de no mínimo dois ciclos estrais consecutivos. Além disso, o bem-estar dessa fêmea deve ser levado em consideração, uma vez que, sob situações de estresse ela não responde ao tratamento superovulatório ou o fazem de forma muito deficiente.

Quando falamos em novilhas púberes para incluir num programa de TE convencional o seu desenvolvimento de massa muscular deve ser representativa de seu peso adulto, 40 a $50 \%$, e o desenvolvimento anátomo-fisiológico tem que estar de acordo com sua idade cronológica e que permita a realização dos procedimentos necessários para coleta de embriões (Reichenbach et al., 2002). 
HONORATO, M.T. et al. Importância da escolha de receptoras em um programa de transferência de embriões em bovinos. PUBVET, Londrina, V. 7, N. 19, Ed. 242, Art. 1601, Outubro, 2013.

\subsection{Aspectos Gerais Relacionados às Receptoras em um Programa de Transferência de Embriões}

As receptoras de embriões também merecem atenção, pois elas são peças fundamentais dentro de um programa de $T E$, porque são elas que vão levar a gestação até o momento do parto. Para serem selecionadas como receptoras as fêmeas devem apresentar: atividade cíclica regular, e quando se tratar de primíparas e pluríparas que estejam paridas há mais de 60 dias; que o puerpério tenha transcorrido normalmente e que estejam livres de doenças ou anomalias do trato reprodutivo (Williams, 2001). Scarpelli (2003) salienta que seria ideal que as fêmeas utilizadas sejam oriundas da mesma propriedade pelo fato de que se tenha conhecimento do histórico produtivo e reprodutivo de cada uma. Porém quando houver necessidade de se comprar fêmeas, que elas estejam com cria ao pé e quando se tratar de novilhas que o seu desenvolvimento corporal esteja adequado a sua idade cronológica e o ciclo estral regular.

Como a avaliação de qualidade zootécnica da receptora não é solicitada, alguns aspectos de seleção devem ser adotados, tais como: porte adequado com a raça do embrião a ser transferido, possibilitando uma gestação e parto normal, evitando partos distócicos (Andrade et al., 2002), bem como apresentar boa habilidade materna e rusticidade (Valentim \&Gofert, 2004).

Segundo Fernandes (2005) o estado de condição corporal da fêmea bovina pode reduzir o desenvolvimento do concepto. A principal fase na qual a nutrição pode afetar o desenvolvimento é no início da gestação, sendo esse efeito particularmente delicado até o reconhecimento materno da gestação, que ocorre entre 17 e 25 dias após a concepção.

Entretanto, o que vai classificar finalmente uma fêmea como apta à transferência ocorre somente no dia da transferência do embrião, pois é baseada nos sinais de estro evidenciados após a realização da sincronização 
HONORATO, M.T. et al. Importância da escolha de receptoras em um programa de transferência de embriões em bovinos. PUBVET, Londrina, V. 7, N. 19, Ed. 242, Art. 1601, Outubro, 2013.

e da avaliação do corpo lúteo funcional (Reichenbach et al., 2002).

De acordo com Neves et al. (2002), o diagnóstico de gestação por palpação retal é um método seguro, que não oferece risco a integridade da receptora e também para a viabilidade do feto, quando realizada por um profissional habilitado. É considerado ainda um método prático e preciso para o diagnóstico em fêmeas bovinas, desde que seja realizado entre $45 \mathrm{e}$ 50 dias de pós-serviço, deve se atentar que a capacidade do examinador tem que ser considerada. Para Reichenbach et al. (2002), esse diagnóstico deve ser realizado de forma precoce, proporcionando assim a possibilidade de utilizar, de forma mais racional, o rebanho de receptoras, assim vai permitir que elas sejam usadas intensivamente em programas sucessivos de TE.

2.3.1 Seleção de receptoras aptas ao processo de transferência de embrião

De acordo com a caracterização do corpo lúteo $(\mathrm{CL})$ informações importantes são fornecidas sobre o estado reprodutivo da fêmea bovina, além de possibilitar o desenvolvimento adequado de procedimentos de manipulação ou sincronização do ciclo estral (Viana et al., 1999). A seleção das receptoras aptas é realizada no dia da transferência de embriõesé feita considerando-se o tamanho do CL mediante palpação transretal. Apesar de ser prático e fácil de ser executado, esse método tem como limitante a baixa sensibilidade e especificidade (Sprecheret al., 1989).

Segundo Viana (1996), a seleção de receptoras realizada através da projeção do $C L$ não é adequada. Um CL com projeção pequena pode ter uma grande porção embebida no estroma ovariano, enquanto que um $\mathrm{CL}$ com projeção maior pode ter massa luteal total pequena. Deste modo a projeção nem sempre está ligada ao tamanho do CL. Uma maneira mais eficiente de avaliar a massa luteal total por palpação transretal é pelo volume aumentado que o $\mathrm{CL}$ proporciona ao ovário no qual está presente (Fernandes \& Velásquez, 1997). 
HONORATO, M.T. et al. Importância da escolha de receptoras em um programa de transferência de embriões em bovinos. PUBVET, Londrina, V. 7, N. 19, Ed. 242, Art. 1601, Outubro, 2013.

\subsubsection{Efeito do manejo e de variáveis bioclimáticas sobre a taxa de gestação} em vacas receptoras de embriões

Nos ambientes tropicais, as elevadas temperaturas do ar, ligada à umidade e radiação alta, diminui consideravelmente a eficiência da perda de calor e, com isso, incrementa o estresse térmico (Silva et al., 2007), o que se torna limitante ao desenvolvimento, a reprodução e produção animal (Torres Júnior et al., 2008). O animal tem a capacidade de se ajustar fisiologicamente mediante estresse por calor, em função de alta umidade do ar e temperatura(o que se observa são a temperatura retal e a frequência respiratória), utilizando esses mecanismos fisiológicos o animal está tentando perder o calor absorvido (Azevedo et al., 2005; Morais et al., 2008). É considerado confortável, um ambiente, quando o animal está em estabilidade, ou seja, quando o calor produzido pelo metabolismo é perdido para o meio ambiente sem prejudicar sua homeostase (Silva, 2000).

É evidente que existem diferenças na resistência ao estresse por calor de acordo com a genética, pois as raças zebuínas tem maior eficiência em regular a temperatura corporal do que as raças de origem européia. Os zebuínos possuem a pele preta sob pêlos claros, condição ideal para se evitar a ação dos raios solares sobre o organismo; além disso, os zebuínos comparados com os taurinos possuem glândulas sudoríparas maiores e mais próximas da superfície corporal, o que facilita a perda de calor por transpiração.Bostaurus(Angus) apresentam temperatura retal maior do que Bosindicus(Brahman) e Bostaurusadaptada (Senepol e Romosinuano), a raça Angus também apresenta frequência respiratória mais rápida que Brahman, Senepol e Romosinuano (Hammondet al., 1996).

O estresse por calor dificulta o desenvolvimento folicular de fêmeas bovinas, pela fragilidade dos folículos ovarianos às altas temperaturas internas. A dominância folicular é deprimida e a dinâmica folicular é modificada (Wolfensonet al., 1995). Essas alterações da dinâmica folicular, que advém do estresse térmico, podem prejudicar o folículo pré-ovulatório prejudicando em seguida a função do corpo lúteo e a secreção de 
HONORATO, M.T. et al. Importância da escolha de receptoras em um programa de transferência de embriões em bovinos. PUBVET, Londrina, V. 7, N. 19, Ed. 242, Art. 1601, Outubro, 2013.

progesterona (Breuelet al., 1993).

Um bom manejo reprodutivo demanda constante contato humano com os animais, e é nesse ponto que o estresse pode ter efeitos negativos sobre a eficiência reprodutiva. Um dos principais efeitos do estresse é a elevação da concentração sanguínea de cortisol (Sapolskyet al., 2000), Debus et al. (2002) afirmam que altas concentrações de cortisol sanguíneo podem levar a prejuízos reprodutivos, mais especificamente ao atraso (ou mesmo inibição) do pico pré-ovulatório do hormônio luteinizante (LH), ocasionando problemas à ovulação, fecundação e/ou qualidade embrionária. O comportamento de cio pode ser anulado ou diminuído sob diferentes circunstâncias, algumas delas são: tipo de piso, inibição social, calor intenso, barulho, etc (Oriuhela, 2000).

Todo fator externo que provoca estresse denomina-se estressor (Encarnação, 1997). Os chamados agentes estressores podem ser de natureza biológica (agentes infecciosos, fatores psíquicos, condição nutricional), mecânica (traumatismos cirúrgicos ou não), química (drogas), física (calor, frio, som) ou ainda uma combinação deles. O frio ou calor culminam em estresse climático que aciona mecanismos fisiológicos no organismo em resposta aos agentes térmicos, com intuito de promover adaptação (Souza et al., 1999).

Estresse crônico ou agudo causam mudanças nos sistemas endócrino, nervoso e imune, o que culmina em modificações no comportamento animal. Algumas respostas ao estresse são: redução do tamanho do bezerro, incapacidade de exibir o estro e baixa taxa de concepção (Varley\&Stedman, 1994).

Vários tecidos do sistema reprodutivo, especialmente o tecido embrionário no período de pré-implantação, são comprometidos por exposição a altas temperaturas. Alterações na duração do ciclo estral, no aumento na percentagem de óvulos anormais e na incidência de morte embrionária são as manifestações mais comumente observadas durante os períodos mais quentes do ano, em decorrência de distúrbios nos 
HONORATO, M.T. et al. Importância da escolha de receptoras em um programa de transferência de embriões em bovinos. PUBVET, Londrina, V. 7, N. 19, Ed. 242, Art. 1601, Outubro, 2013.

mecanismos homeostáticos, com conseqüências diretas sobre a taxa de concepção. Em relação à gestação e ao periparto, observa-se que a exposição de fêmeas prenhez ao estresse por calor resulta em uma elevada incidência de crias mais leves e menos desenvolvidas que o normal, além de um incremento na mortalidade de animais novos (Azêvedo\& Souza, 2007).

2.3.3 Fatores que influenciam a taxa de gestação em receptoras de embriões

É denominado período de gestação o intervalo que vai desde a concepção até o momento do parto. Embora seja determinado geneticamente, pode sofrer modificações por fatores maternos (idade e raça), fetais (tamanho, placenta e sexo), genéticos (raça) e ambientais (estação do ano). A perda da gestação é a responsável pela maior parte das falhas gestacionais em animais domésticos, essa perda pode ser dividida em mortalidade embrionária e mortalidade fetal (Hafez \& Hafez, 2004).

Segundo Molina (2005), a morte embrionária pode acontecer antes do reconhecimento materno, sendo denominada morte embrionária precoce, ou depois deste, sendo chamada de morte embrionária tardia, podendo ser causada por fatores endócrinos, estado nutricional da fêmea e estresse, entre outros. Estes aspectos podem afetar apenas a mãe ou o embrião, em separado, ou ainda afetar a interação materno-embrionária.

Os fatores hormonais resultam do desequilíbrio estrogênioprogesterona o que leva a morte pré-implantação, uma vez que o efeito luteolítico não é impedido ocorrendo assim a regressão do $\mathrm{CL}$, levando a consequente falha gestacional. O suprimento calórico e as deficiências nutricionais afetam as taxas e ovulação e fertilização, causando assim a morte embrionária (Peixoto et al., 2004).

A morte fetal é provocada por causas não infecciosas como a ação de agentes químicos, problemas hormonais, drogas, plantas tóxicas, genéticos e imunológicos, ou por causas infecciosas como protozoários, bactérias, vírus e fungos(Hafez \& Hafez, 2004). 
HONORATO, M.T. et al. Importância da escolha de receptoras em um programa de transferência de embriões em bovinos. PUBVET, Londrina, V. 7, N. 19, Ed. 242, Art. 1601, Outubro, 2013.

Após a transferência dos embriões, a taxa de sobrevivência embrionária pode ser influenciada por fatores como anormalidades cromossômicas, efeito da doadora, idade e qualidade dos embriões transferidos, método e local de transferência, sincronia doadora-receptora, estado nutricional e níveis séricos de progesterona na receptora, bem como o estresse calórico (Ribeiro Filho, 2007).

Além destes, um dos principais fatores ligados à mortalidade embrionária é a concentração de progesterona no período inicial da gestação, devido ao fato de que a progesterona tem papel determinante no processo de placentação e na manutenção do embrião durante a adesão placentária (Araújo, 2005).

Segundo Ball \&Peters (2006), é durante as duas primeiras fases da gestação que ocorrem mais perdas, devendo-se ter atenção especial ao manejo das doadoras até o sétimo dia de gestação, e em seguida o das receptoras a partir do sétimo dia até o final da gestação, em se tratando de TE convencional. Isto para que o embrião possa sinalizar a sua presença à fêmea receptora e impedir a luteólise, que ocorreria se a fêmea não estivesse gestante.

\subsubsection{Diferenças entre as espécies BosTauruse BosIndicus}

Falando em termos de fisiologia, o Bosindicus apresenta um metabolismo mais lento do que Bostaurus. As fêmeas Bosindicus tem um estro de duração mais curta, com maior incidência noturna. As fêmeas Bostaurus têm ciclos estrais com predominância de duas a três ondas em contrapartida as Bosindicus podem ter até quatro ondas por ciclo. Outra diferença consiste no número de folículos recrutados por onda, onde é maior em Bosindicus. Além disso, a puberdade em animais da espécie Bostaurus ocorre mais precocemente do que em Bosindicus, apresentando o folículo dominante e o $\mathrm{CL}$ em menor tamanho do que nas últimas, produzindo menos progesterona (Baruselliet al., 2007).

Outra característica que diferenciaas duas espécies é a obtenção de 
HONORATO, M.T. et al. Importância da escolha de receptoras em um programa de transferência de embriões em bovinos. PUBVET, Londrina, V. 7, N. 19, Ed. 242, Art. 1601, Outubro, 2013.

estágios embrionários mais avançados em Bosindicus quando comparados com os obtidos em Bostaurus. Isso pode ser explicado pelo fato do $\mathrm{LH}$ apresentar uma onda pré-ovulatória entre 20 a 22 horas antes da ovulação ou três a seis horas depois do início do estro em fêmeas Bosindicus, enquanto que em fêmeas Bostaurus esta ocorre de forma mais precoce. Assim, em fêmeas Bosindicus a ovulação ocorre de forma mais precoce, o que pode ser traduzida em fertilizações também mais precoces, o que dá aos embriões tempo adicional para se desenvolverem, permitindo ainda que atinjam estágios de desenvolvimento mais avançados no dia da recolha, quando comparados com os embriões obtidos de fêmeas Bostaurus(Fonseca et al., 2001).

Por último, a duração da gestação em Bosindicus é dez dias mais longa do que em Bostaurus, podendo o anestro pós-parto ser também superior nesta espécie (Baruselli et al., 2007). A Tabela 1 traz um resumo das diferenças entre as espécies.

Tabela 1. Principais diferenças na fisiologia reprodutiva de fêmeas Bostaurus e Bosindicus.

\begin{tabular}{lcc}
\hline & Bosindicus & Bostaurus \\
\hline Duração do estro (horas) & $12,9+/-2,9$ & $16,3+/-4,8$ \\
Número de ondas de crescimento & $2-4$ & $2-3$ \\
folicular & & \\
Diâmetro do folículo ovulatório (mm) & $11,6-12,1$ & $13,9-16,5$ \\
Diâmetro do corpo lúteo (mm) & $17-21$ & $20-30$ \\
\hline
\end{tabular}

Fonte: Barusselliet al. (2007).

\section{CONSIDERAÇÕES FINAIS}

A transferência de embriões é uma biotecnologia reprodutiva que esta sendo empregada para a utilização mais eficiente de animais geneticamente superiores promovendo um incremento nos rebanhos bovinos.

Manejos nutricionais, sanitários e o bem-estar animal são aspectos 
HONORATO, M.T. et al. Importância da escolha de receptoras em um programa de transferência de embriões em bovinos. PUBVET, Londrina, V. 7, N. 19, Ed. 242, Art. 1601, Outubro, 2013.

que não devem ser deixados de lado em nenhum momento dentro de um sistema de produção, sendo empregados desde as doadoras de embriões que possuem um elevado valor agregado até as receptoras que não carregam uma carga genética importante, mas são as responsáveis pela gestação e criação dos descendentes de animais superiores.

\section{REFERÊNCIAS BIBLIOGRÁFICAS}

AMARAL, Tatiana. Goiás Genética 2012 promete grandes participações e novidades na evolução do rebanho.2012. [Online]. Disponível em: http://www.agcz.com.br/sysindex.php?pagina=nav/destaque noticia\&noticia=139. Acesso em: 06 de novembro de 2012.

ANDRADE, J. C. O.; OLIVEIRA, M. A. L.; LIMA, P. F. Use steroid hormone treatments prior to superovulation in Nelore donors. Animal Reproduction Science. Amsterdam, v.69, n.1-2, p.9-14, 2002.

ANDRADE, J. C. O.; OLIVEIRA, M. A. L.; SANTOS FILHO, A. S.; WISCHRAL, A.; LIMA, P. F.; SOUZA, D. M. B. Diferentes protocolos de superovulação em vacas Nelore. Revista Brasileira de Reprodução Animal.v. 23, n.3, p. 317-18, 1999.

ANDRADE, V. J. Manejo reprodutivo de fêmeas bovinos de corte. In: SIMPÓSIO DE PRODUÇÃO DE GADO DE CORTE, 1., 1999, Viçosa. Anais... Viçosa: UFV, 1999. p. 85-135.

ARAÚJO, M. C. C.; VALE FILHO, V. R.; FERREIRA, A. M.; SÁ, W. F.; BARRETO FILHO, J. B.; CAMARGO, L. S. A.; SERAPIÃO, R. V.; SILVA, M. V. G. B. Secreção de interferon-tau em bovinos produzidos in vitro frescos e congelados. Arquivo Brasileiro de Medicina Veterinária e Zootecnia.v. 57, n. 6, p. 751-756, 2005.

AZEVÊDO, D. M.; SOUZA, E. S. O estresse térmico Parte 5: Efeito sobre a reprodução de bovinos leiteiros. 2007. [Online]. Disponível em: http://www.agrolink.com.br/colunistas/ColunaDetalhe.aspx?CodColuna=2789. Acesso em: 06 de novembro de 2012.

AZEVEDO, M.; PIRES, M. F. A.; SATURNINO, H.; LANA, A. M. Q.; SAMPAIO, I. B. M.; MONTEIRO, J. B. N.; MORATO, L. E. Estimativa de níveis críticos superiores do índice de temperatura e umidade para vacas leiteiras $1 / 2,3 / 4$ e $7 / 8$ Holandês-Zebu e lactação. Revista Brasileira de Zootecnia.v. 34, n. 6, p. 2000-2008, 2005.

BALL, P. J. H.; PETERS, A. R. Fertilização, Concepção e Gestação. In: Reprodução em Bovinos. São Paulo: Editora Roca, 2006 3.a ed. p. 53-62.

BARUSSELLI, P. S.; GIMENES, L. U.; SALES, J. N. S. (2007).Fisiologia reprodutiva de fêmeas taurinas e zebuínas. Revista Brasileira de Reprodução Animal.v. 31, n. 2, p. 205-211, 2007.

BAYÃO, Patrícia Peixoto. ExpoBrahman 2012 alia pista à genética diferenciada.2012. [Online]. Disponível em: http://www.brahman.com.br/index.php/noticias/noticias-da-racaacbb/180-expo Acesso em: 15 de outubro de 2012. 
BÓ, G. A.; BARUSELLI, P. S.; MORENO, D.; CUTAIA, L.; CACCIA, M.; TRÍBULO, R.; TRIBBULO, H.; MAPLETOFT, R. J. The control of follicular wave development for selfappointed embryo transfer programs in cattle. Theriogenology. v.57, p.53-72, 2002.

BÓ, G.A. Sincronizacion Del desarrollo folicular y luteal in grupos de donantes y receptoras de embriones bovinos. In:II Curso de abordagem teórico-prática de novas técnicas de sincronização sem observação de cio em bovinos (IA e TE). 2002, Cornélio Procópio-PR. Anais... CornélioProcópio. 2002.

BOLAND, M.P.; GOULDING, D.; ROCHE, J.F. Alternativesgonadotrophins for superovulation in cattle. Theriogenology.v. 35, p. 5-17, 1991.

BRASIL. Ministério da Agricultura e do Abastecimento. Instrução normativa n. 009/99. Veterinária e Zootecnia. Minas. v. 14. n. 62. p. 4-8, 1999.

BREUEL, K.F.; LEWIS, P.E.; SCHRICK, F.N. et al. Factors affecting fertility in postpartum cow: Role of oocyte and follicle in conception rate. Biology of Reproduction.v.48, p.655661, 1993.

BROGLIATTI, G.M.; ADAMS, G.P. Ultrasound-guinedtransvaginal oocyte collection in prepurbetal calves.Theriogenology.v. 45, p. 1163-1176, 1996.

CABODEVILA, J.; TORQUATRI, S. Superovulação de Fêmeas bovinas. In: PALMA, G.A. Biotecnologia de lareproducción. $1^{a}$ edição. INTA, Argentina, 2001. p. 79-108.

COSTA, P. A.; SILVA, F. M. Segurança sanitária em transferência de embriões: revisão bibliográfica. Revista Brasileira de Reprodução Animal.v.28, n.5, p.253-258, 2004.

COSTA, P. V. F da.Transferência de embriões usando a IATF. Centro Regional Universitário, Espírito Santo do Pinhal. São Paulo. p. 84-99, 2005.

CUNNINGHAM, M. J.; CLIFTON, D. K.; STEINER, R. A. Leptin's actions on the reproductive axis: perspectives and mechanisms. BiologyofReproductive.v. 60, p. 216-222, 1999.

DAYAN,A.; WATANABE, M. R.; WATANABE, Y. F. Fatores que interferem na produção comercial de embriões FIV. ArquivoFaculdadeVeterinária UFRGS. v. 28, p. 181-185, 2000.

DEBUS, N.; BREEN, K. M.; BARRELL, G. K.; BILLINGS, H. J.; BROWN, M.; YOUNG, E. A.; KARSCH, F. J. Does cortisol mediate endotoxin-induced inhibition of pulsatile luteinizing hormone and gonadotropin-releasing hormone secretion? Endocrinology, v. 143, p. 3748$3758,2002$.

DEMÉTRIO, D. G. B. Colheita e transferência de embriões bovinos.2003. p. 22-23. Dissertação (Mestrado em Reprodução Animal)- Faculdade de Medicina Veterinária e Zootecnia da UNESP, Campus de Botucatu, São Paulo-SP. 2003.

DINIZ, E. G.; JACOMINI, J. O.; NASCIMENTO, M. R. B. M.; MENDES JR, J. O. B.; ESPER, C. R.. Eficiência de dois diferentes produtos hormonais na superovulação de vacas da raça Nelore. Revista Brasileira de Reprodução Animal.v. 23, n.3, p. 319-20, 1999.

ENCARNAÇÃO, R. O. Estresse e produção animal.30 reimpressão. Campo Grande: EMBRAPA-CNPGC, 1997. 32p. 
FABER, D. C.; MOLINA, J. A.; OHLRICHS, C. L..; VANDER WAAG, D. F.; FERRÉ, L. B. Commercialization of animal biotechnology. Theriogenology.v. 59, p. 125- 138, 2003.

FERNANDES, C. A. C.; VELÁSQUEZ, L. F. U. Características do corpo lúteo e taxa de gestação de receptoras de embrião. Archivos de Reproduction Animal, v. 1, n. 2, p. 2831, 1997.

FERNANDES, C.A. de C. É preciso prestar atenção à mortalidade embrionária. Edição especial DBO Genética.v. 24, n. 299, p. 10-12, 2005.

FERREIRA, A. M. et al. Restrição alimentar e atividade ovariana cíclica pós-parto em vacas girolanda. Pesquisa Agropecuária Brasileira. Brasília, v. 35, n. 12, p. 2521-2528, 2000.

FONSENCA, J. F.; SILVA FILHO, J. M.; PINTO NETO, A.; PALHARES, M. S. Estádios de desenvolvimento embrionário de vacas zebuínas superovuladas. Arquivo Brasileiro de Medicina Veterinária e Zootecnia, v. 53, n. 6, p. 671-676, 2001.

FOSTER, D. L.; NAGATANI, S. Physiological perspectives on leptin as a regulator of reproduction: Role in timing puberty. BiologyofReproduction.v. 60, p. 205-215, 1999.

GONZÁLEZ, F. H. D. Endocrinologia Reprodutiva da Fêmea. In: Introdução a endocrinologia reprodutiva veterinária. [Online]. Porto Alegre: UFRGS, 2002. p. V1V14. Disponível em: http://www.ufrb.edu.br/nera/index.php/artigos-cientificos/13introducao-a-endocrinologia-reprodutAcesso em: 03 de novembro de 2012.

GOODHAND, K. L.; WATT, R. G.; STAINES, M. E. In vivo oocyte recovery and in vitro embryo production from bovine donors aspirated at different frequencies or following $\mathrm{FSH}$ treatment. Theriogenology. Gainesville, v. 51. p. 951-961, 2005.

HAFEZ, E. S. E.; HAFEZ, B. Gestação, Fisiologia Pré-Natal e Parto. In: Reprodução animal.7a Ed. São Paulo: Editora Manole, 2004, p.141-156.

HAFEZ, E. S. E. Reprodução Animal. $4^{\circ}$ ed. São Paulo: Manole, 1988. 720 p.

HAMMOND, A.C.; OLSON, T.A.; CHASE, C.C.Jr. et al. Heat tolerance in two tropically adapted Bos Taurus breeds, Senepol and Romosinuano, compared with Brahman, Angus and Hereford cattle in Florida. Journal Animal Science.v.74, p. 295-303, 1996.

HENDRIKSEN, P. J. M.; STEENWEG, W. N. M.; HARKEMA, J. C.; MERTON, J. S.; BeVERS, M. M.; VOS, P. L. A. M.; DIELEMAN, S. J. Effect of different stages of the follicular wave on in vitro developmental competence of bovineoocytes. Theriogenology. v. 61, p. 909-902, 2004.

LONERGAN, P.; MONAGHAN, P.; RIZOS, D.; BOLAND, M. P.; GORDON, I. Efect of follicle size on bovine oocyte quality and development competence following maturation, fertilization and culture in vitro. Molecular ReproductionandDevelopment. v. 37, p. 48$53,1994$.

MAPLETOFT, R. J.; STOOKEY, J. M. Procedimentos sanitários gerais e considerações de bem estar associados com a produção in vivo de embriões. In: InternationalEmbryoTransferSociety. USA, abril, 1998. Tradução: OLIVEIRA FILHO, E. B. Manual da Sociedade Internacional de Transferênciade Embriões. Uberlândia: SBTE, 1999. Cap. 4, p.57-70.

MAPLETOFT, R. J.; STEWARD, K. B.; ADAMS, G. P. Recent advances in the superovulation in cattle. Reproduction Nutrition Development. v. 42, p. 601-611, 2002. 
MEINTJES, M.; BELLOW, M. S.; BROUSSARD, J. R.; PAUL J. B.; GODKE, R. A. Transvaginal aspiration of oocytes from hormone-treated pregnant beef for in vitro fertilization. Journal Animal Science. v. 73, p. 967-974, 1995.

MERTON, J. S.; ROOS, A. P. W.; MULLAART, E.; RUIGH, L.; KAAL, L.; VOS, P. L. A. M.; DIELEMANI. Factors affecting oocyte quality and quantity in commercial application of embryo technologies in the cattle breeding industry.Theriogenology.v. 59, n. 2, p. 651$674,2003$.

MOLINA, L. Mortalidade embrionária em bovinos: Interrelações embrião-patógenos (Parte $\quad$ II). $2005 . \quad$ [Online]. Disponível em: http://rehagro.com.br/plus/modulos/noticias/ler.php?cdnoticia=1118. Acesso em: 1 de novembro de 2012.

MORAIS D. A. E. F.; MAIA, A. S. C.; SILVA, R. G.; VASCONCELOS, A. M.; LIMA, P. O.; GUILHERMINO, M. M. Variação anual de hormônios tireoideanos e características termorreguladoras de vacas leiteiras em ambiente quente. Revista Brasileira de Zootecnia.v. 37, n. 3, p. 538-545, 2008.

MUNAR, C. J.; VALDEZ, A. M.; BEN, G.; MUJICA, I. F. Seleccion de receptoras y sincronizacion de celosen bovinos. La Plata, RA.: cristal. p. 2-9. 2001.

NEVES, J. P.; OLIVEIRA, J. F. C.; MACIEL, M. N. Diagnóstico de gestação em bovinos. In: GONSALVES, P. B. D.; FIGUEIREDO, J. R.; FREITAS, V. J. F. Biotécnicas aplicadas à reprodução animal. São Paulo: Varela, 2002. Cap. 1, p 1-13.

NIBART, M.; SILVA PEIXER, M.; THUARD, J.M.; DURANT, M.; GUYADER-JOLY, C.; PONCHON, S.; MARQUANT-LE GUIENNE, B.; HUMBLOT, P. Embryo production by OPU and IVF in dairy cattle. In: Réunion A.E.T.E., XI, Hannover, Proceedings, p. 216, 1995.

ORIHUELA, A. Some factors affecting the bhaviouralmanifestatuin of oestrus in cattle: a review. Applied Animal Behaviour Science.v. 70, n. 1, p. 1-16, 2000.

PARRA, B. C.; PARRA, B. S.; ZANGIROLAMI FILHO, D.; BUENO, A. P.; PICCININ, A. Aspecto Sanitário na Transferência de Embriões de Bovinos. Revista Científica Eletrônica de Medicina Veterinária. [Online]. Ano VI, n. 10. 7 p. Janeiro de 2008. Periódico Semestral. Disponível em: http://www.revista.inf.br/veterinaria10/revisao/edic-vi-n10-RL08.pdf Acesso em: 17 de outubro de 2012.

PEIXOTO, M. G. C. D.; BERGMANN, J. A. G.; ALVIM, M. T. T.; PENNA, V. M. Fatores que influenciaram a prenhez de embriões zebuínos em receptoras mestiças. In: Simpósio da Sociedade Brasileira de Melhoramento Animal, Pirassununga, SP: SBMA, 2004. $4 p$.

REICHENBACH, H.; OLIVEIRA, M. A. L.; LIMA, P. F.; SANTOS FILHO, A. S.; ANDRADE, J. C. $O$. Transferência e criopreservação de embriões bovinos. In: GONSALVES, P. B. D.; FIGUEIREDO, J. R.; FREITAS, V. J. F.Biotécnicas aplicadas à reprodução animal. São Paulo: Varela, 2002. cap.8, p.127-177.

RENESTO, Andréa. Associação das Biotécnicas: Aspiração Folicular Guiada por UltraSonografia e Superovulação na Produção In Vitro e In Vivo de Embriões Bovinos. 2004. 59 p. Dissertação (Mestrado em Reprodução Animal)-UNESP/Jaboticabal, São Paulo, 2004.

RIBEIRO FILHO, A. L. Apontamentos de apoio às aulas da disciplina de Inseminação Artificial em Bovinos e Andrologia - UFBA, Salvador, Bahia, Brasil (2007). 
RIGOLON, L. P.; PRADO, I. N.; CAVALIERI, F. L. B.; NASCIMENTO, W. G.; BETINI, C. M; CANALLI, I. C. Efeito do nível de ingestão de energia na dieta na produção de embriões em novilhas de corte: resultados preliminares. Arquivos da Faculdade de Veterinária da UFRGS - Sociedade Brasileira de Transferência de Embriões. Porto Alegre, 2000. v. 28, n. 1, p. 321.

RODRIGUES, J. L. Transferência de Embriões Bovinos - Histórico e Perspectivas Atuais. Revista Brasileira De Reprodução Animal.v. 25, n. 2, p. 102-107, 2001.

SANTOS, J. E. P. Importância da alimentação na reprodução da fêmea bovina. In: I Workshop sobre reprodução animal. 2000. Pelotas. Anais... Pelotas: EMBRAPA, 2000, p. 782.

SAPOLSKY, R. M.; ROMERO, M. L.; MUNCK, A. U. How do glucocorticoids influence stress responses? Integrating permissive, suppressive, stimulatory, and preparative actions. Endocrinology, v. 89, p. 21-55. 2000.

SCARPELLI, L. C. Sincronização do ciclo estral em bovinos. São Paulo: Pharmacia Saúde Animal, 2003. 14p.

SENEDA, M. M.; W. BLASCHI, K. C.P.; RUBIN, L. A. Aspiração folicular in vivo: metodologias, eficiência e seqüelas. In: Congresso Brasileiro de Reprodução Animal, n. 16, 2005, Goiânia, GO. Anais... Palestras. Londrina-PR: UEL, 2005.

SILVA, R. G. Introdução à bioclimatologia animal. São Paulo: Nobel, 2000. 450p.

SILVA, R. G.; MORAIS, D. A. E. F.; GUILHERMINO, M. M. Evaluation of thermal stress indexes for dairy cows in tropical regions.Revista Brasileira de Zootecnia.v. 36, n. 4, p. 1192-1198 (supl.), 2007.

SIMÃO, G. Exportação de genética revoluciona o zebu. Anuário DBO, São Paulo, 2004. n. 280, p.46.

SOUZA, C. F.; FAÇANHA, D. A. E.; COSTA E SILVA, E. V. Influência do ambiente sobre o desempenho de bovinos de corte. Seminário (Disciplina de Bovinos de Corte, Programa de Pós Graduação em Zootecnia) - Unesp, Jaboticabal, 1999.

SPRECHER, D. J.; NEBEL, R. L; WHITMAN, S. S.The predective value, sensitivity and specificity of palpation per rectum and transrectal ultrasonography for the determination of bovine luteal status.Theriogenology. v. 31, p. 1165-1172, 1989.

SUTMOLLER, P. Importation of bovine genetics: a quantitative risk assessment of disease transmission by bovine embryo transfer. Annals of the New York Academy of Sciences.v.23. p. 269-270, 1996.

THIBIER, M. The IETS statistics of embryo transfers in livestock in the world for the year 1999: A new record for bovune in vivo-derived embryos transferred. Embryo Transfer Newsletter. v. 18, p. 24-28, 2000.

TORRES JÚNIOR, J. R. S.; PIRES, M. F. A.; SÁ, W. F.; FERREIRA, A. M.; VIANNA, J. H. M.; CAMARGO, L. S. A.; RAMOS, A. A.; FOLHADELLA I. M.; POLISSENI, J.; FREITAS, C.; CLEMENTE, C. A. A.; SÁ FILHO, M. F.; PAULA-LOPES, F. F.; BARUSELLI, P. S. Effect of maternal heat-stress on follicular growth and oocyte competence in Bosindicus cattle. Theriogenology.v. 69, p. 155-166, 2008. 
VALENTIM, R.; GOFERT, L. Conceitos sobre sincronização de receptoras. 2004. [Online]. Disponível em http://www.beefpoint.com.br/radarestecnicos/reproducao/conceitos-sobre-sincronizacao-de-receptoras-17964/. Acesso em: 23 de outubro de 2012.

VARLEY, M.; STEDMAN, R. Stress and reproduction. In: OLE, D.J.A.; WISEMAN, J. and VALEY, M.A. (ed). Principles of pigs science. Nottingham, UK: Nottingham University Press, 1994. P.277-297.

VIANA, J. H. M. Avaliação ultra-sonográfica de estruturas ovarianas em doadoras e receptoras de embrião. 1996. 120 f. Dissertação (Mestrado) - Departamento de Zootecnia, Viçosa, MG. Departamento de Zootecnia, Universidade Federal de Viçosa, Viçosa, 1996.

VIANA, J. H. M.; FERREIRA, A. M.; SÁ, W. F.; CAMARGO, L. S. A. Características morfológicas e funcionais do corpo lúteo durante o ciclo estral em vacas da raça Gir. Arquivo Brasileiro de Medicina Veterinária e Zootecnia.v. 51, n. 3, p. 251-256, 1999.

VIANA, J. H. M.; CAMARGO, L. S. A.; FERREIRA, A. M.; SÁ, W. F.; FERNANDES, C. A. C.; ARAÚJO, M. C. C.; RA-MOS, A. A.; MARQUES JR, A. P. Ovarian pre-stimulation with FSH, active immunization against inhibin and folli-cular aspiration results in Gir cattle (Bosindicus). Theriogenology.v.57, p.630, 2002.

VIANA, J. H. M.; NASCIMENTO, A. A.; PINHEIRO, N. L.; FERREIRA, A. M; CAMARGO, L. S. A.; SÁ, W. F.; MARQUES JR, A. P. Caracterização de sequelas subsequentes à punção folicular em bovinos. Pesquisa Veterinária Brasileira. v. 23, p.119-124, 2003.

VISINTIN, J.A.; ARRUDA, R.P.; MADUREIRA, E.H.; MIZUTA, K.; CELEGHINI, E.C.C.; ASSUMPÇÃO, M.E.O.A.; GUSMÕES, P.P.G.; CANDINI, P.H. Superovulação de novilhas da raça Nelore com diferentes doses de FSH/LH e congelação de embriões pelo método onestep com etilenoglicol. Brazilian Journal of VeterinaryResearch and Animal Science. v. 36. n. 5, 1999

WILLIAMS, G. L. Implicações de amamentação e manejo de cria na eficiência reprodutiva futura de vacas de corte. $\mathbf{V}$ Curso novos enfoques na produção e reprodução de bovinos.Uberlândia, 2001.p. 65.

WOLFENSON, D.; THACHER, W.W.; BADINGA, L. el al.A Effect of heat stress on follicular development during the estrous cycle in lactating dairy cattle. Biology of Reproduction.v. 52, p. $1106-1113,1995$. 